\title{
Biological Evaluation and Computational Studies of Methoxy-flavones from Newly Isolated Radioresistant Micromonospora Aurantiaca Strain TMC-15
}

\section{Wasim Sajjad}

National University of Medical Sciences

Mahnoor Nadeem

Quaid-i-Azam University Faculty of Biological Sciences

Tayyaba Alam

Quaid-i-Azam University Faculty of Biological Sciences

Asim ur Rehman

Quaid-i-Azam University Faculty of Biological Sciences

Fariha Hasan

Quaid-i-Azam University Faculty of Biological Sciences

Samiullah Khan

Quaid-i-Azam University Faculty of Biological Sciences

Malik Badshah

Quaid-i-Azam University Faculty of Biological Sciences

Sumra Wajid Abbasi

National University of Medical Sciences

\section{Sajjad Ahmad}

Quaid-i-Azam University Faculty of Biological Sciences

Ghufranud Din

University of Haripur

Muhammad Farman

Quaid-i-Azam University Faculty of Biological Sciences

Aamer Ali Shah ( $\nabla$ alishah@qau.edu.pk)

Quaid-i-Azam University Faculty of Biological Sciences https://orcid.org/0000-0001-7454-4105

\section{Research Article}

Keywords: Antioxidant, Eupatilin, Hydroxyauranetin, LC-MS, Micromonosporaaurantiaca, Radioresistant

Posted Date: January 31st, 2022 
DOI: https://doi.org/10.21203/rs.3.rs-1277398/v1

License: (c) (1) This work is licensed under a Creative Commons Attribution 4.0 International License. Read Full License 


\section{Abstract}

This study aims to determine UV-B resistance and to investigate computational analysis and antioxidant potential of methoxy-flavones of Micromonospora aurantiaca TMC-15 isolated from Thal Desert, Pakistan. The cellular extract was purified through solid phase extraction and UV-Vis spectrum analysis indicated absorption peaks at $\lambda_{\max } 250 \mathrm{~nm}, 343 \mathrm{~nm}$, and $380 \mathrm{~nm}$ that revealed the presence of methoxyflavones named eupatilin and 5-hydroxyauranetin. The flavones were evaluated for their antioxidant as well as protein and lipid peroxidation inhibition potential using di(phenyl)-(2,4,6-trinitrophenyl) iminoazanium (DPPH), 2,4-dinitrophenyl hydrazine (DNPH), and thiobarbituric acid reactive substances (TBARS) assays, respectively. The methoxy-flavones were further studied for their docking affinity and interaction dynamics to determine their structural and energetic properties at atomic level. The antioxidant potential, protein and lipid oxidation inhibition and DNA damage preventive abilities were correlated as predicted by computational analysis. The eupatilin and 5-hydroxyauranetin binding potential to their targeted proteins $1 \mathrm{~N} 8 \mathrm{Q}$ and $10 \mathrm{G} 5$ is -4.1 and $-7.5 \mathrm{kcal} / \mathrm{mol}$, respectively. Moreover, the eupatiline and 5-hydroxyauranetin complexes illustrate van der Waals contacts and strong hydrogen bonds to their respective enzymes target. Both in-vitro studies and computational analysis results revealed that methoxy-flavones of Micromonospora aurantiaca TMC-15 can be used against radiation mediated oxidative damages due to its kosmotrophic nature. The demonstration of good antioxidant activities not only protect DNA but also protein and lipid oxidation and therefore could be a good candidate in radio-protective drugs and as sunscreen due to its kosmotropic nature.

\section{Introduction}

Low-wavelength radiation is highly mutagenic and can damage all living organisms. Some radioresistant extremophiles have adapted themselves to thrive in the presence of high levels of radiation by effective scavenging abilities of reactive oxygen and nitrogen species (Fredrickson et al., 2008). Microorganisms residing in such extreme habitats can evolve faster as compare to those living in benign environment ( $\mathrm{Li}$ and Hong, 2016). This is associated to the high mutation rate in such harsh conditions which ultimately could lead to put selective pressure on these microbes as a result, produce something interesting of biotechnological use (Sayed et al., 2020). Diverse metabolic properties in radioresistant organisms include production of extremozymes, carotenoids, flavonoids, vitamins and other potential extremolytes that can scavenge reactive radicals (Yu et al., 2015). Radioresistant extremophiles act as host for novel compounds that are not only important for their structural and biochemical diversity but also devise biotechnological applications in food, cosmetics and pharmaceutical industries. Such metabolic products not only aid in the survival of microorganisms in extreme environment but also play a role in conditions like desiccation resistance, involved in immunosuppression, enhancing antioxidant and anticancer properties, enabling oxidative damage repair (Nair et al., 2004). The exploration of radioresistant extremophiles has helped to develop bio-products for novel and improved drugs that offer protection to lipids, proteins, and nucleic acids (Waditee-Sirisattha et al., 2016). The demand of 
radioresistant, protective biomolecules has increased in the pharmaceutical and biotechnological industries (Galano et al., 2010).

Various extremolytes have been extracted from radioresistant bacteria in search for radioprotective biomolecules. Flavonoid metabolites are promising as effective antioxidant candidates (Lee et al., 2009) as they can interfere with signal transduction pathways and limit proliferation and metastasis.

Flavonoids counter with reactive radicals and produce stabilized and inactive radicals (Hanasaki et al., 1994). Flavonoids can also directly scavenge free radicals. To date, there is limited information available on bioactive compounds form radiation resistant bacteria although radioresistant bacteria are ubiquitous in the environment (Beblo-Vranesevic 2017). Some of the extremophiles are also found in the genus Micromonospora, belongs to Actinobacteria. These actinobacteria have biosynthetic gene clusters, which encode various biosynthetic pathways of potentially useful metabolites (Li and Hong, 2016). Extreme environments have vast diversity of actinobacteria that could be the source of radiation protective metabolites. Actinobacteria isolated from hot spring has also been recently evaluated for bioactivities which exhibited strong antibacterial activity against many pathogenic microbes (Mehetre et al., 2019). Some studies showed that the cell wall of Micromonospora isolated form high altitude Atacama Desert soil contains meso- and hydroxy-diaminopimelic acid, and glycolipids (Carro et al., 2019). A recent study conducted on microbial colonization process on solar panel surfaces and its effect on photovoltaic efficiency also revealed the presence of extremophilic bacterial genera Deinococcus, Hymenobacter and Roseomonas and fungal Neocatenulostroma (Tanner et al., 2020).

In the present study, a radiation-resistant bacterium was isolated from a soil sample of the Thal Desert. Subsequently, the growth conditions and in-vitro biological activities of flavones were characterized for this radioresistant isolate. The intracellular methanol-soluble compounds from the isolated strain was extracted and purified for characterization and further bioactivities. The radiation-protective properties of the metabolites were screened with a view to potential biotechnological applications with emphasis on nutraceutical industry.

\section{Materials And Methods}

\section{Isolation of UV-B radiation resistant strains}

Soil samples were collected from the Thal Desert Pakistan, diluted serially and plated on tryptone glucose yeast extract agar (TGY) containing (per liter) $5 \mathrm{~g}$ tryptone, $1 \mathrm{~g}$ glucose, $5 \mathrm{~g}$ yeast extract, and $1 \mathrm{~g} \mathrm{~K}_{2} \mathrm{HPO}_{4}$, $\mathrm{pH}$ 7.0. Before incubation, the plates were exposed to UV radiation for $5 \mathrm{~min}$ in a UV-B chamber $(119 \times 69 \times$ $52 \mathrm{~cm}$ ) supplied with $280 \mathrm{~nm}$ UV light of $20 \mathrm{~W}$. The rate of UV fluency (energy/area/time $\left(\mathrm{J} / \mathrm{m}^{2}\right)$ for test samples was calculated by using the formula $\mathrm{He}=\mathrm{Ee} \times \mathrm{t}$ where $\mathrm{He}$ is radiant exposure, Ee is energy of irradiance and $t$ is the time duration maintained during radiation exposure (Sajjad et al., 2017). The survival curves were determined by sub-culturing the bacteria from the radiated plates.

\section{Bacterial survival under UV-B radiation and oxidative stress}


The resistance of strain TMC-15 to UV-B radiation, hydrogen peroxide and mitomycin $\mathrm{C}$ was tested by plotting the survival curve as described previously by Mattimore and Battista (1996). The cell culture was serially diluted (1:000) optical density $\left(\mathrm{OD}_{600}\right)$ of 0.08-0.1 (McFarland standard) in sterile phosphate buffer solution (PBS) pH 7.0 and spread on TGY agar plates, followed by exposure to various doses of UV-B radiations at $280 \mathrm{~nm}$ and incubation for 3 to 7 days at $35^{\circ} \mathrm{C}$. The survival was estimated by dividing total number of colonies on radiated plates to colonies on non-radiated (control) plates. For oxidative stress determination, strain TMC-15 $\left(\mathrm{OD}_{600}\right.$ of $\left.0.08-0.1\right)$ was treated with $10-60 \mathrm{mM} \mathrm{H}_{2} \mathrm{O}_{2}$ and 2-10 $\mu \mathrm{g} / \mathrm{ml}$ mitomycin-C for $30 \mathrm{~min}$, followed by plating on TGY and incubation at $35^{\circ} \mathrm{C}$ for 3 to 7 days. The relative survival was calculated as the difference in the number of colonies between the treated and untreated cultures. All experiments for the survival curve were run in triplicate.

\section{Bacterial identification}

Molecular identification was carried out by extracting DNA, using a modified SDS based DNA extraction method (Xia et al., 2019). 16S rRNA gene sequences were then amplified with universal primers 27F (5'AGAGTTTGATCMTGGCTCAG-3') and 1492R (5'-TACGGYTACCTTGTTACGACTT-3'). The PCR amplicons were sequenced at Macrogen Service Center (GeunChun-gu, Seoul, South Korea) and computed by using basic local alignment search tool (BLAST) and compared with homologous sequences in databases of NCBI for nearest relatives. A neighbor-joining tree was constructed using MEGA X (Kumar et al., 2018) for identification of strain TMC-15 and compared with already reported strains in NCBI GenBank for acquisition of accession number. The 16S rRNA sequence of strain TMC-15 was submitted to NCBI GenBank under the accession number MN721337.

\section{Extraction of intracellular bioactive compounds from strain TMC-15}

Strain TMC-15 was grown under optimum conditions with continuous shaking at $150 \mathrm{rpm}$. The cells were harvested by centrifugation $(5000 \times \mathrm{g})$ for $15 \mathrm{~min}$ at $4^{\circ} \mathrm{C}$, and the cell pellets were washed using PBS $(\mathrm{pH}$ 7.4) before placed at $-4{ }^{\circ} \mathrm{C}$ for cold shock. Methanol was added to the pellets and disrupted repeatedly by sonication until the suspension became yellow colored. The suspension was centrifuged, then passed through syringe filter $(0.22 \mu \mathrm{m}$ pore size $)$ and finally dried out in order to remove the solvent.

\section{Characterization of bioactive compounds from strain TMC- 15}

\section{Fourier transform Infra-Red (FT-IR) analysis}

The methanolic extract was vacuum evaporated to collect the sticky material (yellow pigment) and was further subjected to drying at $30^{\circ} \mathrm{C}$, the compound once purified using SPE C18 cartridge was subjected to FTIR analysis. The purified extract (10 mg sample) was mixed with $100 \mathrm{mg} \mathrm{KBr}$ for Fourier Transform Infra-Red (FTIR) analysis (Jiao et al., 2010). Absorption measurement was taken over the wavelength range of 400 to $4500 \mathrm{~cm}^{-1}$ and the spectra were recorded using a Spectrum 65 FTIR spectrometer 
(PerkinElmer). The extract was re-dissolved in methanol and the spectrum in the range of $200-800 \mathrm{~nm}$ was recorded with UV-Vis spectrophotometry.

\section{Liquid Chromatography-Mass Spectrometry (LC-MS) analysis}

The purified extract (solid phase extraction) was analyzed with an Agilent 6310 Ion Trap LC-MS. The extract was dissolved in methanol (LC-MS grade) and injected to column (C18, internal diameter $5 \mu \mathrm{m}$, $150 \times 4.6 \mathrm{~mm}$ ). Mobile phase was in isocratic mode consisting of acetonitrile: water (80:20) with 0.5 $\mathrm{ml} / \mathrm{min}$ flow rate. The MS was used in negative ion mode to detect mass to charge $(\mathrm{m} / \mathrm{z})$ transitions $[\mathrm{M}+\mathrm{H}]^{-}$. The data was resolved with Thermo Scientific Xcalibur ${ }^{\mathrm{TM}}$ software.

\section{Bioassays of purified extract from strain TMC-15 \\ Antioxidant activity by Diphenyl-1-picrylhydrazyl (DPPH) scavenging assay}

The DPPH scavenging rate of the purified intracellular extract was measured by the method as previously described (Ebrahimzadeh et al., 2008). The reaction mixture contained $20 \mu \mathrm{l}$ DPPH (0.1 mM) and $180 \mu \mathrm{l}$ of the sample at different concentration (10-50 $\left.\mu \mathrm{g}^{-1}\right)$. The assay mixture $(200 \mu \mathrm{l})$ was incubated in dark for $30 \mathrm{~min}$ at $30^{\circ} \mathrm{C}$ before the absorbance was measured at $517 \mathrm{~nm}$. Ascorbic acid (10-50 $\left.\mu \mathrm{g} \mu \mathrm{l}^{-1}\right)$ was used as a positive control. The relative scavenging activity was calculated using the formula [(Control absorbance - sample absorbance)/control absorbance] ×100.

\section{Iron chelation assay}

Iron chelation activity was determined by adding $50 \mu \mathrm{l}$ of $2 \mathrm{mM}$ ferrous chloride to $10-50 \mu \mathrm{g} \mathrm{l}^{-1}$ of the purified sample (Zhao et al., 2008). The reaction was initiated by adding $20 \mu$ of ferrozine (5 mM). The assay mixture was incubated at room temperature for $15 \mathrm{~min}$ in dark and the absorbance at $562 \mathrm{~nm}$ was

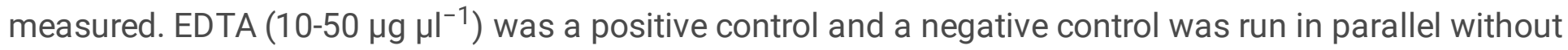
any chelating agent.

\section{Protein carbonylation assay}

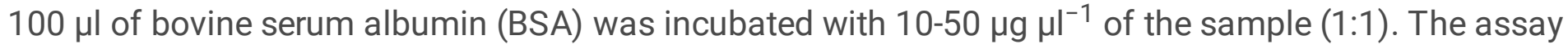
mixture received $50 \mu \mathrm{FeSO}_{4}(1 \mathrm{mM}), 50 \mu \mathrm{l}$ of $\mathrm{H}_{2} \mathrm{O}_{2}(80 \mathrm{mM})$. The mixture was incubated for $1 \mathrm{~h}$ at room temperature and the reaction was stopped by adding 2-3 drops of catalase. This mixture was incubated with $300 \mu \mathrm{l}$ 2, 4-dinitrophenylhydrazine (DNPH) $(10 \mathrm{mM})$ for $1 \mathrm{~h}$ in dark and vortexed after every $10 \mathrm{~min}$. The unbound protein was precipitated by adding $50 \mu \mathrm{l}$ of chilled 10\% trichloroacetic acid (TCA). Protein precipitates were washed with 50\% ethyl acetate and ethanol (1:1) (Sobeh et al., 2019). TCA was evaporated and precipitates were centrifuged at $2000 \times \mathrm{g}$ at $4{ }^{\circ} \mathrm{C}$ for $10 \mathrm{~min}$ after adding $1 \mathrm{ml}$ of guanidine hydrochloride $(6 \mathrm{M})$. Absorbance of the supernatant was measured at $370 \mathrm{~nm}$ compared to a 
blank run in parallel by replacing $\mathrm{H}_{2} \mathrm{O}_{2}$ and $\mathrm{FeSO}_{4}$ with distill water. Percentage inhibition was calculated from [(Absorbance of control - Absorbance of sample)/ Absorbance of control] $\times 100$.

\section{Lipid peroxidation inhibition assay}

Thiobarbituric acid assay was performed by measuring lipid peroxidation inhibition offered by flavones. 1 $\mathrm{g}$ rat liver tissue was fused (Bio-Gen PRO200 homogenizer) in Tris- $\mathrm{HCl}$ buffer at $\mathrm{pH} 7.4$ and centrifuged at $3000 \times g$ for $5 \mathrm{~min}$. An aliquot $(1 \mathrm{ml})$ was mixed with $10-50 \mu \mathrm{g} \mathrm{\mu l}^{-1}$ of the sample. The reaction was initiated by mixing $300 \mu \mathrm{l}$ of $\mathrm{FeSO}_{4}(10 \mathrm{Mm}), 200 \mu$ l sodium dodecyl sulphate (SDS) (8.1\%), $250 \mu$ l acetic acid, and $250 \mu$ thiobarbituric acid (TBA) $(0.6 \% \mathrm{v} / \mathrm{v})$. The assay mixture was incubated for $1 \mathrm{~h}$ at $100{ }^{\circ} \mathrm{C}$ before the absorbance was measured at $532 \mathrm{~nm}$. Finally, the lipid peroxidation inhibition was calculated using malondialdehyde (MDA) standard curve.

\section{DNA protection activity}

The DNA damage prevention assay was determined by incubating pUC18 plasmid $(2 \mu \mathrm{l})$ treated with 10 $\mu \mathrm{g} \mathrm{l}^{-1}$ of purified sample, $3 \mu \mathrm{l}$ of $\mathrm{FeSO}_{4}(2 \mathrm{mM}), 4 \mu \mathrm{l}$ of $\mathrm{H}_{2} \mathrm{O}_{2}(30 \%), 4 \mu$ of sodium nitroprusside $(1 \mathrm{mM})$ followed by incubation for $1 \mathrm{~h}$ at $37^{\circ} \mathrm{C}$ (Kitts et al., 2000). Double and single stranded breakage of pUC18 was generated by the attack of hydroxyl radical, observed in the negative control. In the positive control, untreated DNA was run in parallel prior to addition of any DNA damaging agents. The DNA bands of the treated extract, the negative and positive controls were separated using agarose gel electrophoresis.

\section{Computational Studies}

\section{Molecular Docking}

Molecular docking of the compounds with representative two enzymes that respond to production of reactive oxygen species was accomplished using Autodock 4.2.6 (Morris et al., 2009). Initially, the enzymes 3D structure of the cytochrome P450 (PDB ID: 10G5) and lipoxygenase (PDB ID: 1N8Q) were retrieved from protein data bank (Bermen et al., 2000) and subsequently treated in a short receptor preparation phase. During this phase, all co-crystalized ligands were removed from the receptors and hydrogen atoms were added. Energy minimization was performed to remove steric clashes in the enzymes structure limiting steepest descent steps to 100 , conjugate gradient steps to 10 and setting the step size to $0.02 \AA$. AMBER ff 14 SB force field was applied on the structure to treat standard residues whereas to specify net charge for the receptors AM1-BCC charge method was used. The docking procedure used in this study following protocol described by Costa et al., (2018). Before, the docking method was validated by docking the co-crystalized ligand at the same position presented in the crystal structure. For both compounds, 10 iterations were produced and ranked as per binding affinity for the receptors (binding energy in $\mathrm{kcal} / \mathrm{mol}$ ). Coordinates of the grid center for IN8Q on XYZ were set as: $21.864 \AA$, $2.184 \AA$ and $18.909 \AA$ whereas for $10 G 5$ it is $-20.257 \AA, 86991 \AA$, and $38.581 \AA$. The grid six points for $1 \mathrm{~N} 8 \mathrm{Q}$ were $24 \mathrm{X}, 18 \mathrm{Y}$ and $12 \mathrm{Z}$, while for $10 \mathrm{G} 5$ they were $22 \mathrm{X}, 20 \mathrm{Y}$ and $24 \mathrm{Z}$. Conformation with high affinity (lowest binding energy) among the predicted poses was selected as complex with the enzyme to be visualized for interactions and put forward possible interaction mechanism. 


\section{Molecular Dynamics (MD) simulations}

The selection of screened small compounds for potential optimization using MD simulations depends not only on the docking energies but also on interacting residues, fitness scores, pharmacophoric and low toxicity features. The study of conformational behavior of selected compounds in complex with macromolecules at atomic level is an important step in providing an insight into the structural stability, physico-chemical behavior, and biological mechanisms. In view of this, we performed a 50ns MD simulation for the prioritized complexes using AMBER 18. Using antechamber, a module embedded in Amber18, a set of initial parameters and libraries was generated (Case et al., 2008). In tleap module, ff14SB force field for proteins and GAFF for ligands were used to investigate the stability and dynamical

properties of selected compounds and dock complexes. In orthorhombic TIP3P water box at $8.0 \AA$, the top scoring docked conformations of all the four systems were solvated. After that, the $\mathrm{Na}+$ ions were added to neutralize the systems. Energy optimization was accomplished via 2000 steps minimization of hydrogen atoms, 1000 steps minimization of system solvation box energy with the restraint of 200 $\mathrm{kcal} / \mathrm{mol}-\AA 2$ on the rest of the system, 1000 steps minimization of the entire set of system atoms with the restraint of $5 \mathrm{kcal} / \mathrm{mol}-\AA 2$ exercised on system carbon alpha atoms, and 300 steps minimization on non-heavy atoms of the system with the restraint of $100 \mathrm{kcal} / \mathrm{mol}-\AA 2$ on the remaining components of the system. The system was then heated to $300 \mathrm{~K}$ through the NVT ensemble supported via Langevin dynamics and SHAKE algorithm to limit hydrogen bonds. An equilibration for 100-ps was attained while sustaining pressure on the system via NPT ensemble letting restraint on Ca atoms of $5 \mathrm{kcal} / \mathrm{mol}-\AA 2$ (Abbasi et al., 2016; Naz et al., 2020). The resulting trajectories, using the CPPTRAJ module, were examined, for the structural stability (Roe and Cheatham 2013).

\section{MMPB/GBSA analysis for binding free energies}

The MMPB/GBSA method approach was further applied on the simulation trajectories to estimate free binding energy of all the four system as a difference between the receptor proteins, ligands and receptorligand complexes free energies (Miller et al., 2012). The MMPB/GBSA free binding energy is computed using equation:

$\Delta G_{\text {bind }}=G_{\text {receptor-ligand }} \otimes\left(G_{\text {receptor }}+G_{\text {ligand }}\right)$

For each term, the free energy is decomposed into MM energy, polar and nonpolar solvation energy and entropy, as demonstrated by the following equation:

$\Delta \mathrm{G}=\Delta \mathrm{E}_{\text {molecular mechanics }}+\Delta \mathrm{G}_{\text {solvation }}-\mathrm{T} \cdot \Delta \mathrm{S}=\Delta \mathrm{E}_{\text {sum of angles }}+\Delta \mathrm{E}_{\text {van der Waals }}+\Delta \mathrm{E}_{\text {electrostatic }}+\Delta \mathrm{G}_{\text {solvation, }}$ polar $+\Delta \mathrm{G}$ solvation, non-polar $-\mathrm{T} \cdot \Delta \mathrm{S}$

The delta MMPB/GBSA energy of the compounds is calculated from 100 snapshots extracted from the simulation trajectories.

\section{Statistical analysis}


Survivability of strain TMC-15 isolated from desert soil following exposure to different energy levels of ultraviolet B (UV-B) radiation. a UV radiation-resistant potential of WMA-LM9, b resistance to different concentrations of hydrogen peroxide $\left(\mathrm{H}_{2} \mathrm{O}_{2} ; \mathrm{mM}\right)$, c resistance to different concentrations of mitomycin $\mathrm{C}$ $(\mu \mathrm{g} / \mathrm{ml})$. Percentage survivability value is calculated as $\mathrm{N} 1 / \mathrm{N} 0 \times 100$ where $\mathrm{Ni}$ is the value after exposure to irradiation, $\mathrm{H}_{2} \mathrm{O}_{2}$ or mitomycin $\mathrm{C}$, and $\mathrm{N} 0$ is the value at time 0 , for each condition tested. Results are highly significant among different groups at $p<0.05$ (Student's unpaired t test). Values are given as the mean \pm standard deviation (SD; error bars) of triplicate experiments. Percentage scavenging activity of flavones were studied by regression analysis between the ability to quench the superoxides and their respective concentrations. Single factor and two-way analysis of variance were applied for analysis of DPPH, iron chelation, lipid and protein oxidation inhibition assays. All the experiments were run in triplicates $(n=3)$. The vertical error bars represent standard deviation values $( \pm$ S.D.).

\section{Results}

\section{Sample collection and screening of UVR microbes}

The results of bacteriological analysis of sand samples collected during summer months have shown 18 UV-resistant isolates from Thal desert. Majority of them were chromogenic where isolate TMC- 15 showed high resistant to UV rays and was also able to produce pigments on the surface of TGY agar plates.

\section{Oxidative stress resistance in TMC-15}

Strain TMC-15 exhibited $56 \%$ survival at $4.068 \times 10^{3} \mathrm{~J} / \mathrm{m}^{2}$ of UV radiation ( $280 \mathrm{~nm}$ ) (Fig. 1a), $53 \%$ survival in the oxidative stress test with $40 \mathrm{mM}$ of $\mathrm{H}_{2} \mathrm{O}_{2}$ (Fig. $1 \mathrm{~b}$ ), and $52 \%$ survival at $6 \mu \mathrm{g} / \mathrm{ml}$ of mitomycin-C (Fig. 1). E. coli was run as control which unable to sustain on high dose of UV radiation and high concentration of $\mathrm{H}_{2} \mathrm{O}_{2}$, mitomycin $\mathrm{C}$. survival of Strain TMC- 15 gradually decreased with increase in concentration of all the three variables. Results are expressed as means $\pm S D$ and were compared using the Student's unpaired t-test. Moreover, the percentage values had an exponential distribution. Error bars represent standard deviation for triplicate experiments. $P<0.05$ is considered significant.

\section{Identification of strain TMC-15}

Gram staining revealed that isolate TMC-15 is Gram positive. Biochemical characteristics revealed that strain is catalase positive, with pale orange, pointed, small colonies on TGY agar plates. 16S rRNA gene sequencing of TMC-15 demonstrated closest alignment to the phylum actinobacteria, genus Micromonospora. A phylogenetic tree constructed by Neighbor-Joining method presented $100 \%$ match of strain TMC-15 with Micromonospora aurantiaca MH588238 (Fig. 2).

Characterization of cellular extract from M. aurantiaca strain TMC-15

\section{FT-IR analysis}


The FTIR spectra (Fig. 3) revealed peaks at $3258 \mathrm{~cm}^{-1}$ representing $\mathrm{OH}$ group of alcohols and peaks in the range 2921 and $2851 \mathrm{~cm}^{-1}$ representing $\mathrm{C}-\mathrm{H}$ groups of alkanes. The peak at $1736 \mathrm{~cm}^{-1}$ represented the presence of aromatic compounds and the 1223 and $1066 \mathrm{~cm}^{-1}$ peaks represent ether linkages (Table 2). The purified intracellular extract was scanned between 200 to $800 \mathrm{~nm}$. The absorption spectra $\lambda_{\max }$ for the purified fraction dissolved in methanol was noted at $343 \mathrm{~nm}, 250 \mathrm{~nm}$ and $380 \mathrm{~nm}$.

Table 1

Antioxidant activities of intracellular compound extracted in comparison to their respective standard (control)

\begin{tabular}{|c|c|c|c|c|c|}
\hline Concentration in $\mu \mathrm{g} \mathrm{ml}^{-1}$ & 10 & 20 & 30 & 40 & 50 \\
\hline \multicolumn{6}{|l|}{ DPPH Radical Scavenging Assay } \\
\hline $\begin{array}{l}\text { \% inhibition of Test } \\
\text { (Intracellular extract) }\end{array}$ & 70.43 & 72.2 & 74 & 87.3 & 96.1 \\
\hline$\%$ inhibition of Control (Ascorbic acid) & 80.2 & 88 & 91.2 & 95.3 & 97.61 \\
\hline \multicolumn{6}{|l|}{ Iron chelation Assay } \\
\hline $\begin{array}{l}\text { \% inhibition of Test } \\
\text { (Intracellular extract) }\end{array}$ & 34 & 61 & 66 & 76 & 87.3 \\
\hline \% inhibition of Control (EDTA) & 65.4 & 72.68 & 76.5 & 89 & 92.9 \\
\hline \multicolumn{6}{|l|}{ Protein oxidation Inhibition Assay } \\
\hline $\begin{array}{l}\% \text { protein oxidation inhibition of Control (Ascorbic acid) } \\
\text { on BSA }\end{array}$ & 70.34 & 72.85 & 74.55 & 87.3 & 96.1 \\
\hline $\begin{array}{l}\% \text { protein oxidation inhibition of Control (Ascorbic acid) } \\
\text { on mice liver }\end{array}$ & 77 & 79.1 & 79.1 & 81.2 & 84 \\
\hline$\%$ inhibition of Control (Ascorbic acid) & 80 & 88 & 91.2 & 95.33 & 97.61 \\
\hline \multicolumn{6}{|l|}{ Lipid Per-oxidation Inhibition Assay } \\
\hline $\begin{array}{l}\% \text { Lipid per-oxidation inhibition of Test (Intracellular } \\
\text { extract) }\end{array}$ & 25.5 & 33.2 & 42.3 & 55 & 70.2 \\
\hline $\begin{array}{l}\text { \% Lipid per-oxidation inhibition of Control (Ascorbic } \\
\text { acid) }\end{array}$ & 44 & 56 & 60.2 & 70 & 75.1 \\
\hline
\end{tabular}


Table 2

Wave number recorded, type of bond present and functional group representation in FTIR analysis.

\begin{tabular}{|lll|}
\hline Wave Number $\left(\mathrm{cm}^{-1}\right)$ & Bond & Functional Group \\
\hline 3258 & O-H & Alcohol \\
2921 & C-H & Alkane \\
2851 & C-H & Alkane \\
1736 & C-H & Aromatic Compound \\
1633 & C=C & Alkene \\
1466 & C-H & Alkane \\
1403 & O-H & Alcohol, Carboxylic \\
1223 & C-O & Ether \\
\hline 1066 & C-O & Ether \\
\hline
\end{tabular}

\section{LC-MS analysis}

The methanol-soluble extract exhibited a pool of peaks at a retention time of $2.8 \mathrm{~min}$, with two major peaks at highest intensity (Fig. 4). The mass scan width in the negative ion mode was 100-1000. Major peaks for $\mathrm{m} / \mathrm{z} 343.9$ and 386.9 matched the formula $\mathrm{C}_{18} \mathrm{H}_{16} \mathrm{O}_{7}$ and $\mathrm{C}_{20} \mathrm{H}_{20} \mathrm{O}_{8}$, corresponding eupatilin (5,7-dihydroxy-3', 4', 6-trimethoxyflavone) and hydroxyauranetin (5-hydroxy-3,6,7,8,4'pentamethoxyflavone).

Bioassays of purified extract from M. aurantiaca strain TMC-15 DPPH radical scavenging assay

The flavones (eupatilin and hydroxyauranetin) effect on DPPH radical scavenging is shown in Table 1, increased with concentration of the purified extract. $80 \%$ scavenging activity was offered by flavones when used at concentration of $50 \mu \mathrm{g} \mathrm{ul}^{-1}$. Ascorbic acid was run in parallel as positive control, showed $97 \%$ scavenging activity in pure form.

\section{Lipid peroxidation and protein carbonylation assays}

The role of flavones (eupatilin and hydroxyauranetin) against oxidative damage to lipid and protein was also studied. The oxidative effect on protein (BSA) and lipid (rat liver homogenate) was inhibited $73 \%$ and $51 \%$, respectively. The standard ascorbic acid $\left(50 \mu \mathrm{g} \mathrm{l}^{-1}\right)$ showed $79 \%$ inhibition (Table 1 ).

\section{Iron chelation assay}


Oxidative damage of cellular component due to free available iron in the body is extensively linked to degenerative diseases. These free $\mathrm{Fe}^{+2}$ can generate superoxides through Fenton pathway. The electron donating potential of such compounds are also very affective in metal ion chelation as shown in Table 1 (87\%) when compared with standard EDTA.

\section{DNA damage protection assay}

Several metabolic processes generate toxic superoxides and other active $\mathrm{OH}$ species. These freely available $\mathrm{O}$ and $\mathrm{OH}$ ions attack on DNA resulting oxidative damages. DNA damages have extensively studied for its relevance to pathogenesis of multiple diseases. Here, we investigated the DNA preventive effect of eupatilin and hydroxyauranetin using plasmid pUC18 with $\mathrm{H}_{2} \mathrm{O}_{2}, \mathrm{FeSO}_{4}$ and sodium nitroprusside. The gel electrophoresis results indicated that oxidative damage to plasmid pUC18 was inhibited by flavones as shown in figure 5 .

\section{Computational studies}

\section{Molecular docking analysis}

The docking protocol was validated first by docking the co-crystalized ligands at the site reported in the crystal structure. The results revealed similar compounds conformation both in docking and crystal structures thus validating the accuracy of docking protocol. For 5-hydroxyauranetin, the top docked conformation has binding affinity of $-3.2 \mathrm{kcal} \mathrm{mol}^{-1}$ to $1 \mathrm{~N} 8 \mathrm{Q}$ and $-7.0 \mathrm{kcal} / \mathrm{mol}$ for $10 \mathrm{G} 5$. The eupatilin binding potential for $1 \mathrm{~N} 8 \mathrm{Q}$ and $10 \mathrm{G} 5$ is $-4.1 \mathrm{kcal} \mathrm{mol}^{-1}$ and $-7.5 \mathrm{kcal} \mathrm{mol}^{-1}$, respectively. The interactions of compound to receptor molecules at the docked positions are provided in Figure 6. Eupatilin complexes with their target enzymes illustrates strong hydrogen bonding and intramolecular ligand Van der Waals interactions as shown in figure 7.

\section{Molecular dynamics simulation}

Both compounds in complex with the enzymes (1N8Q and 10G5) were subjected to dynamics understanding. In general, all the four complexes depicted very stable behavior as demonstrated by the Ca-RMSD. This concludes strong intermolecular binding and stable conformation of the compound with the receptors. The mean Ca-RMSD computed for the complexes is: $1 \mathrm{~N} 8 \mathrm{Q}-5$-Hydroxyyauranetin (1.7 $\AA$ ),

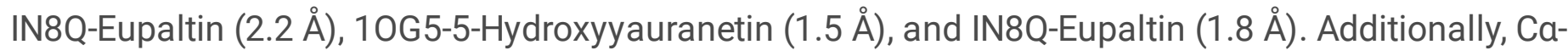
RMSF of all complexes were estimated to examine residual flexibility of the enzyme residues in the compound presence.

In order to get insights of conformation stability, the RMSD of compounds was plotted versus simulation time. As shown in figure 8, the compounds original docked conformation is quite stable.

\section{MMPB/GBSA analysis}

The docking affinity of the compounds for the enzymes was tested further using popular binding energy methods of MMGBSA and MMPBSA. All the four complexes demonstrated rigorous binding energies as 
tabulated in Table 3. To the net energy of complexes, significant binding energy contribution was noticed from gas phase in both MMGBSA and MMPBSA whereas the solvation energy contribution is likely to be less important in complex formation. In the solvation phase, non-polar energy somewhat plays a role in binding contrast to the polar solvation contribution.

Table 3

Binding energies of the docked complexes.

\begin{tabular}{|c|c|c|c|c|c|}
\hline Method & $\begin{array}{l}\text { Energy } \\
\text { Component }\end{array}$ & $\begin{array}{l}\text { 1N8Q-5-Hydro- } \\
\text { xyyauranetin }\end{array}$ & $\begin{array}{l}\text { IN8Q- } \\
\text { Eupaltin }\end{array}$ & $\begin{array}{l}\text { 10G5-5-Hydro- } \\
\text { xyyauranetin }\end{array}$ & $\begin{array}{l}\text { 10G5- } \\
\text { Eupaltin }\end{array}$ \\
\hline \multirow[t]{7}{*}{ MMGBSA } & VDWAALS & -52.82 & -57.51 & -42.35 & -50.2933 \\
\hline & EEL & -269.83 & -32.26 & -30.66 & -36.5203 \\
\hline & EGB & 280.48 & 47.40 & 50.64 & 48.5143 \\
\hline & ESURF & -7.27 & -6.44 & -5.57 & -5.5441 \\
\hline & DELTA G gas & -322.66 & -89.78 & -73.02 & -86.8136 \\
\hline & DELTA G solv & 273.21 & 40.95 & 45.07 & 42.9702 \\
\hline & $\begin{array}{l}\text { DELTA } \\
\text { TOTAL }\end{array}$ & -49.45 & -48.83 & -27.94 & -43.8434 \\
\hline \multirow[t]{8}{*}{ MMPBSA } & VDWAALS & -52.82 & -57.51 & -42.35 & -50.2933 \\
\hline & EEL & -269.83 & -32.26 & -30.66 & -36.5203 \\
\hline & EPB & 267.61 & 55.64 & 46.66 & 61.2405 \\
\hline & ENPOLAR & -3.76 & -3.55 & -3.97 & -3.7890 \\
\hline & EDISPER & 0.0000 & 0.0000 & 0.00 & 0.0000 \\
\hline & DELTA G gas & -322.6620 & -89.7878 & -73.02 & -86.8136 \\
\hline & DELTA G solv & 263.8484 & 52.0852 & 42.69 & 57.4516 \\
\hline & $\begin{array}{l}\text { DELTA } \\
\text { TOTAL }\end{array}$ & -58.8136 & -37.7026 & -30.3279 & -29.3621 \\
\hline
\end{tabular}

\section{Discussion}

Thal desert of Pakistan has been characterized by high solar radiation, salinity and wide temperature fluctuation between day and night. There is no available literature to explore these extreme environments in search of new strains able to produce valuable compounds. Most of the isolates characterized in our study were able to produce colored colonies on solid agar medium. The chromogenic factor of these microbes might be helpful in their protection against UVB induced oxidative damage. Previously a number of studies have been carried out to isolate radio-resistant bacteria from desert soil, the radiation resistant property is acquired as a result of evolution that protect cells from desiccation (Rainey et al., 
2005). The ability of these UVR microbes to survive in several extreme conditions, is suggested to be as a result of modulating gene expression in extreme conditions (Li et al., 2014) thereby producing colored compounds, shield the bacterium in stress. There is also a strong correlation between mitomycin $\mathrm{C}, \mathrm{H}_{2} \mathrm{O}_{2}$ resistance and secondary metabolite production. The ability of radioresistant microbes to survive in extreme conditions is suggested to be a result of three combined mechanisms: prevention, tolerance and repair. The results also suggested that TMC-15 has a strong catalase and superoxide dismutase antioxidant system thereby protecting the cell from oxidative damages and showed prolong resistance to all three variables.

The phylum actinobacteria is ubiquitous and considered one of the most valuable eco-friendly prokaryotes in field of microbial biotechnology. Recently, methanolic extract from genus Micromonospora isolated from extreme hyper-arid Atacama Desert soil evaluated for biotechnological potential (Carro et al., 2019). There are several putative genes of Micromonospora that cope stress responses (Trujillo et al., 2014; Brettin et al., 2015) such as heat shock, cold shock, desiccation, and oxidative stress. M. aurantiaca has genes associated with SOS repair and also superoxide dismutase genes. In recent years, better understanding of ROS-induced oxidative damages and searching for new bioactive molecules and novel strategies to protect the cellular damages are the two major goals of medical research. Our results revealed that intracellular eupatilin and hydroxyauranetin, confer protection against oxidative stress conditions. There are no previous reports on eupatilin and 5-hydroxyauranetin in radio-resistant bacteria. The results from in-vitro biological activities suggested that the intracellular extract from strain TMC-15 scavenges free radicals, comparable to properties reported for radio resistant Deinococcus strains (Slade et al., 2011; Sajjad et al., 2017). The strong scavenging potential of these compounds may also be due to conjugated double bond and resonance structure which can easily transfer or donate electron to form final stable product. The presence of keto, hydroxy groups and active fractions like quercetin and gallic acid analogs contributing to such antioxidant activities (Yang et al., 2011).

Flavones have potential as chemotherapeutic drug for different pathological conditions related to free radicals. The antioxidant results offered by these flavones against free radicals generated by $\mathrm{FeSO}_{4}$ in protein oxidation inhibition assay are due to the capability of such compounds to donate electrons thereby neutralizing the free radicals. In our study the flavones extracted from this bacterium was more efficient in preventing the protein and lipid oxidative damages as studied in BSA and mice liver homogenate (Prazdnova et al., 2014). The kosmotrophic nature of the studied flavones also aids to decrease the solubility of different cellular membranes and strengthen the intermolecular hydrogen bonding to maintain the integrity of membranes and prevent leakage of cellular contents (Krinsky and Johnson 2005). Due to conjugation double bond system, resonance structure and presence of keto groups, such compounds result in the formation of relatively stable end products which suggests that it can be effectively used in drugs and for other therapeutic applications.

The biological significance of iron and predominantly its pathological concerns are due to its involvement in the oxidation-reduction process known as the HaberWeiss reaction where it generates different super oxides that have deleterious effects on the cells, resulting in mitochondrial damage, DNA oxidation and 
peroxidation of membrane lipids. Moreover, the free iron can react with unsaturated lipids resulting production of alkoxyl and peroxyl radicals. The consequences of iron-overload are apparent in diseases such as thalassemia, Friedreich's ataxia and other pathological conditions that lead to cancer (Heli et al., 2011; Kolnagou et al., 20014). Through a series of reactions these flavones through oxidation-reduction mechanism form stable end products thereby prevent the cells from oxidative damage by blocking the Fenton reactions and by quenching super oxides. Iron chelation therapy signifies a novel strategy of treatment for these disorders, preventing oxidative effects by removing catalytically active iron. The gel electrophoresis results indicated that oxidative damage to plasmid pUC18 was inhibited by flavones. The possible mechanism might be due to the inhibition of 7,8-oxo-2-deoxyguanosine formation generated in stress (Sajjad et al., 2017). This study also showed that many other DNA repair enzymes, cellular proteins, enzymatic antioxidants are protected by these flavones. The protective ability of the studied flavones contributes to prolong the cell survival in extreme conditions and significantly reduces the DNA damage risk (Singh and Gabani 2011). Eupatilin and 5-hydroxyauranetin have significant industrial and pharmaceutical importance, and now there is a potential for producing them in bioreactors.

The antioxidant potential of purified compounds was additionally investigated computationally to decipher their binding affinity to selected receptors. Both compounds bound exactly to the same site of the enzymes and interact with common set of residues. The 5-hydroxyauranetin to $1 \mathrm{~N} 8 \mathrm{Q}$ formed two strong hydrogen bonds with lle857 and His518 additional to strong network of hydrophobic contacts. This compound prefers to interact hydrophobically with the enzyme residues. Eupatilin complexes with their target enzymes illustrates strong hydrogen bonding and intramolecular ligand van der Waals interactions as shown in figure 7. It was observed that in the presence of compound, enzyme residues in all four complexes are significantly stable with exception to 1N8Q-Eupaltin where Asp20-Phe40 region showed higher fluctuations. Upon inspection, fluctuation in this region is the outcome of flexible loop covering residue of Pro1-Asn 12 and may be an approach to hold the compound strongly at the docked site. The average Ca-RMSF of the complexes is: 1N8Q-5-Hydroxyyauranetin (0.8 $\mathrm{A})$, IN8Q-Eupaltin (1.2 $\AA$ ), 10G5-5-Hydroxyyauranetin (0.8 $\AA$ ), and IN8Q-Eupaltin (0.9 $)$. The 1N8Q-Eupaltin as discussed earlier is showing some variation in the binding mode that might be driven by the N-terminal loop to accomplish proper intermolecular binding and enhance complex stability. For each compound, average RMSD with enzyme is: $1 \mathrm{~N} 8 \mathrm{Q}-5$-Hydroxyyauranetin $(0.5 \AA)$, IN8Q-Eupaltin $(0.7 \AA), 10 \mathrm{G} 5-5$-Hydroxyyauranetin $(0.5 \AA)$, and IN8Q-Eupaltin (0.4 ̊̊).c

Finally, it is concluded that Micromonospora aurantiaca strain TMC-15 isolated form extreme environment showed high rate of tolerance to $\mathrm{UV}, \mathrm{H}_{2} \mathrm{O}_{2}$ and mitomycin. The flavones from strain TMC- 15 exhibited both antioxidant as well as oxidative damage prevention potential against cellular macromolecules. The docking analysis also revealed significant binding affinity of these flavones to their target proteins through $\mathrm{N}$-terminal loop. Both eupatilin and 5-hydroxyauranetin can be used as potential mitigator and radioprotectants in sunscreen to overcome the radiation mediated oxidative damages. Further studies are needed to determine biosynthetic pathway for enhanced production and intensified bioactivities through metabolic engineering. 


\section{Declarations}

\section{Funding}

This work was funded by Higher Education Commission of Pakistan.

\section{Conflict of interest}

The authors declare no conflict of interest.

\section{Ethics approval}

The current study does not include any human or animal subject; therefore, the ethical committee approval is not required.

\section{Author Contributions}

WS, MN, TA and AAS: Preparation of the overall research plan as well as protocols for various experiments

WS, MN, AR: Performed experimental work in lab as per the pre-designed research plan

$\mathrm{GD}, \mathrm{FH}, \mathrm{SK}$ and MB: Facilitated in interpretation of various bioassay and phylogenetic analysis in the current research project

SWA and SA: Contributed in docking and simulation analysis

MF: Analysis of samples through LC-MS and interpretation of LC-MS data.

WS, MN, AR, AAS: Write up of the manuscript

AAS, FH, SK, MB: Proof reading of the oveall mansucript for english comprehension and typing mistakes

\section{Acknowledgements}

This study was supported by the Higher Education Commission of Pakistan.

\section{References}

1. Abbasi S, Raza S, Azam SS, Liedl KR, Fuchs JE (2016) Interaction mechanisms of a melatonergic inhibitor in the melatonin synthesis pathway. J Mol Liq 221:507-17

2. Beblo-Vranesevic K, Galinski EA, Rachel R, Huber H, Rettberg P (2017) Influence of osmotic stress on desiccation and irradiation tolerance of (hyper)-thermophilic microorganisms. Arch Microbiol 199(1):17-28 
3. Berman HM, Westbrook J, Feng Z, Gilliland G, Bhat TN, Weissig H, Shindyalov IN, Bourne PE (2000) The protein data bank. Nucleic Acids Res 28(1):235-42

4. Brettin T, Davis JJ, Disz T, Edwards RA, Gerdes S, Olsen GJ, Olson R, Overbeek R, Parrello B, Pusch GD, Shukla M (2015) RASTtk: a modular and extensible implementation of the RAST algorithm for building custom annotation pipelines and annotating batches of genomes. Sci Rep 5:8365

5. Carro L, Castro JF, Razmilic V, Nouioui I, Pan C, Igual JM, Jaspars M, Goodfellow M, Bull AT, Asenjo JA, Klenk HP (2019) Uncovering the potential of novel micromonosporae isolated from an extreme hyper-arid Atacama Desert soil. Sci Rep 9(1):1-6

6. Carro L, Golinska P, Nouioui I, Bull AT, Igual JM, Andrews BA, Klenk HP, Goodfellow M (2019) Micromonosporaacroterricola sp. nov., a novel actinobacterium isolated from a high altitude Atacama Desert soil. Int J Syst Evol Microbiol 69(11):3426-36

7. Case, D. A., Darden, T. A., Cheatham III, T. E., Simmerling, C.L., ... Kollman, P.A. (2018). AMBER 18, University of California, San Francisco

8. Costa JD, Ramos RD, Costa KD, Brasil DD, Silva CH, Ferreira EF, Borges RD, Campos JM, Macêdo WJ, Santos CB (2018) An in silico study of the antioxidant ability for two caffeine analogs using molecular docking and quantum chemical methods. Molecules 23(11):2801

9. Ebrahimzadeh MA, Pourmorad F, Hafezi S (2008) Antioxidant activities of Iranian corn silk. Turk J Biol 32(1):43-9

10. Fredrickson JK, Shu-mei WL, Gaidamakova EK, Matrosova VY, Zhai M, Sulloway HM, Scholten JC, Brown MG, Balkwill DL, Daly MJ (2008) Protein oxidation: key to bacterial desiccation resistance? ISME J 2(4):393-403

11. Galano A, Vargas R, Martínez A (2010) Carotenoids can act as antioxidants by oxidizing the superoxide radical anion. Phys Chem Chem Phys 12(1):193-200

12. Hanasaki Y, Ogawa S, Fukui S (1994) The correlation between active oxygens scavenging and antioxidative effects of flavonoids. Free Radic Biol Med 16(6):845-50

13. Heli H, Mirtorabi S, Karimian K (2011) Advances in iron chelation: an update. Expert OpinTher Pat 21(6):819-56

14. Jiao Y, Cody GD, Harding AK, Wilmes P, Schrenk M, Wheeler KE, Banfield JF, Thelen MP (2010) Characterization of extracellular polymeric substances from acidophilic microbial biofilms. Appl Environ Microbiol 76(9):2916-22

15. Kitts DD, Wijewickreme AN, Hu C (2000) Antioxidant properties of a North American ginseng extract. Mol Cell Biochem 203(1-2):1-0

16. Kolnagou A, Kontoghiorghe CN, Kontoghiorghes GJ (2014) Transition of Thalassaemia and Friedreich ataxia from fatal to chronic diseases. World J Methodol 4(4):197

17. Krinsky NI, Johnson EJ (2005) Carotenoid actions and their relation to health and disease. Mol Aspects Med 26(6):459-516 
18. Kumar S, Stecher G, Li M, Knyaz C, Tamura K (2018) MEGA X: molecular evolutionary genetics analysis across computing platforms. Mol Biol Evol 35(6):1547-9

19. Lee YK, Yuk DY, Lee JW, Lee SY, Ha TY, Oh KW, Yun YP, Hong JT (2009) (-)-Epigallocatechin-3-gallate prevents lipopolysaccharide-induced elevation of beta-amyloid generation and memory deficiency. Brain Res 1250:164-74

20. Li L, Hong K (2016) Micromonosporaovatispora sp. nov. isolated from mangrove soil. Int J Syst Evol Microbiol 66(2):889-93

21. Li SJ, Hua ZS, Huang LN, Li J, Shi SH, Chen LX, Kuang JL, Liu J, Hu M, Shu WS (2014) Microbial communities evolve faster in extreme environments. Sci Rep 4:6205

22. Mattimore V, Battista JR (1996) Radioresistance of Deinococcusradiodurans: functions necessary to survive ionizing radiation are also necessary to survive prolonged desiccation. J Bacteriol 178(3):633-7

23. Mehetre GT, Vinodh JS, Burkul BB, Desai D, Santhakumari B, Dharne MS, Dastager SG (2019) Bioactivities and molecular networking-based elucidation of metabolites of potent actinobacterial strains isolated from the Unkeshwar geothermal springs in India. RSC Advances 9(17):9850-9

24. Miller III BR, McGee Jr TD, Swails JM, Homeyer N, Gohlke H, Roitberg AE (2012) MMPBSA. py: an efficient program for end-state free energy calculations. J Chem Theory Comput 8(9):3314-21

25. Morris GM, Huey R, Lindstrom W, Sanner MF, Belew RK, Goodsell DS, Olson AJ (2009) AutoDock4 and AutoDockTools4: Automated docking with selective receptor flexibility. J Comput Chem 30(16):2785-91

26. Nair CK, Salvi V, Kagiya TV, Rajagopalan R (2004) Relevance of radioprotectors in radiotherapy: studies with tocopherol monoglucoside. J Environ PatholToxicol Oncol 23(2)

27. Naz S, Ahmad S, Walton S, Abbasi SW (2020) Multi-epitope based vaccine design against Sarcoptesscabieiparamyosin using immunoinformatics approach. J Mol Liq 319:114105

28. Prazdnova EV, Dem'yanenko SV, Chistyakov VA, Lysenko VS, Batyushin MM (2014) Carotenoidsantioxidants of D. radiodurans stimulate regeneration in mice. Biol Med6(3):1

29. Rainey FA, Ray K, Ferreira M, Gatz BZ, Nobre MF, Bagaley D, Rash BA, Park MJ, Earl AM, Shank NC, Small AM (2005) Extensive diversity of ionizing-radiation-resistant bacteria recovered from Sonoran Desert soil and description of nine new species of the genus Deinococcus obtained from a single soil sample. App Environ Microbiol 71(9):5225-35

30. Roe DR (2013) Cheatham III TE. PTRAJ and CPPTRAJ: software for processing and analysis of molecular dynamics trajectory data. J Chem Theory Comput 9(7):3084-95

31. Sajjad W, Ahmad M, Khan S, Ilyas S, Hasan F, Celik C, McPhail K, Shah AA (2017) Radio-protective and antioxidative activities of astaxanthin from newly isolated radio-resistant bacterium Deinococcus sp. strain WMA-LM9. Ann Microbiol 67(7):443-55

32. Sayed AM, Hassan MH, Alhadrami HA, Hassan HM, Goodfellow M, Rateb ME (2020) Extreme environments: microbiology leading to specialized metabolites. J App Microbiol 128(3):630-57 
33. Singh OV, Gabani P (2011) Extremophiles: radiation resistance microbial reserves and therapeutic implications. J App Microbiol 110(4):851-61

34. Slade D, Radman M (2011) Oxidative stress resistance in Deinococcusradiodurans. Microbiol Mol Biol Rev 75(1):133-91

35. Sobeh M, Petruk G, Osman S, El Raey MA, Imbimbo P, Monti DM, Wink M (2019) Isolation of myricitrin and 3, 5-di-0-methyl gossypetin from syzygiumsamarangense and evaluation of their Involvement in protecting keratinocytes against oxidative stress via activation of the Nrf-2 pathway. Molecules 24(9):1839

36. Tanner K, Molina-Menor E, Latorre-Pérez A, Vidal-Verdú À, Vilanova C, Peretó J, Porcar M (2020) Extremophilic microbial communities on photovoltaic panel surfaces: a two-year study. MicrobBiotechnol 13(6):1819-30

37. Trujillo ME, Bacigalupe R, Pujic P, Igarashi Y, Benito P, Riesco R, Médigue C, Normand P (2014) Genome features of the endophytic actinobacterium Micromonosporalupini strain Lupac 08: on the process of adaptation to an endophytic life style? PLoS One 9(9):e108522

38. Waditee-Sirisattha R, Kageyama H, Takabe T (2016) Halophilic microorganism resources and their applications in industrial and environmental biotechnology. AIMS Microbiol 2(1):42-54

39. Xia Y, Chen F, Du Y, Liu C, Bu G, Xin Y, Liu B (2019) A modified SDS-based DNA extraction method from raw soybean. Biosci Rep 39(2)

40. Yang H, Dong Y, Du H, Shi H, Peng Y, Li X (2011) Antioxidant compounds from propolis collected in Anhui, China. Molecules 16(4):3444-55

41. Yu LZ, Luo XS, Liu M, Huang Q (2015) Diversity of ionizing radiation-resistant bacteria obtained from the Taklimakan Desert. J Basic Microbiol 55(1):135-40

42. Zhao H, Fan W, Dong J, Lu J, Chen J, Shan L, Lin Y, Kong W (2008) Evaluation of antioxidant activities and total phenolic contents of typical malting barley varieties. Food Chem 107(1):296-304

\section{Figures}



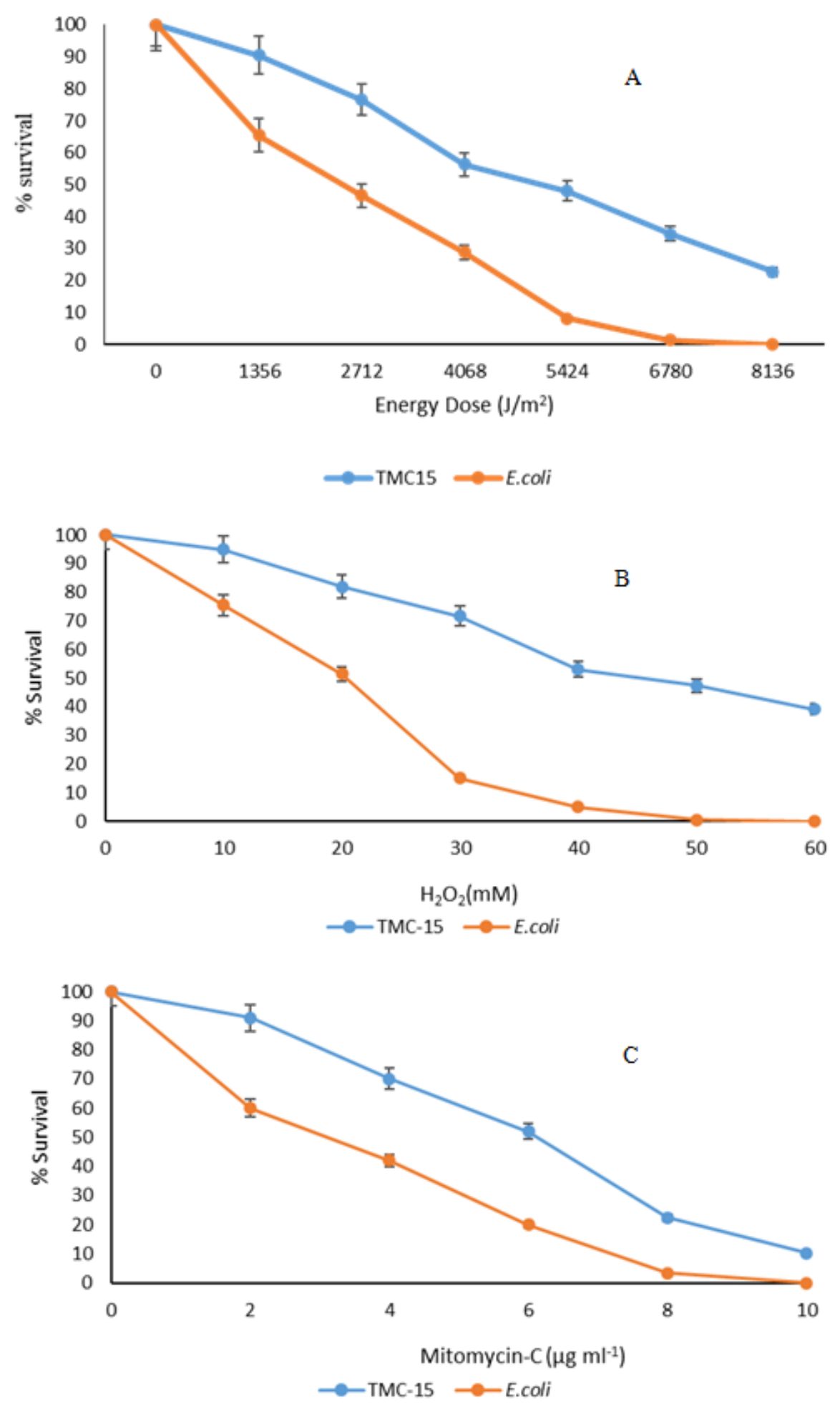

\section{Figure 1}

Survival of UV-resistant strain TMC-15 to different oxidative stresses. (A)UV-B radiation resistance potential of strain TMC-15 in comparison to UV-sensitive E. coli; (B)Resistance to different concentrations of $\mathrm{H}_{2} \mathrm{O}_{2}$; (C) Resistance to different concentrations of mitomycin-C 


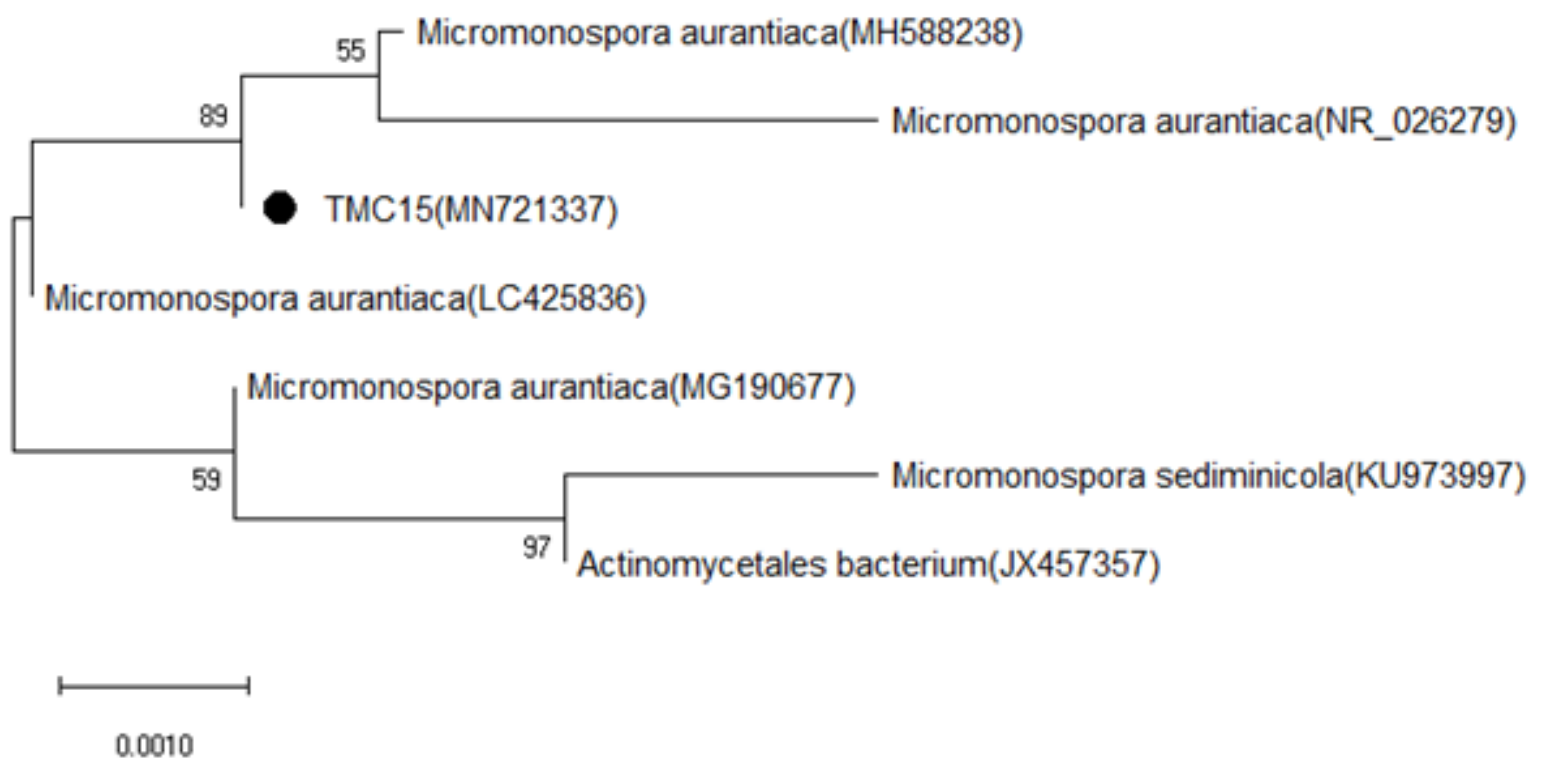

Figure 2

Neighbor-joining phylogenetic tree based on 16S rRNA gene sequencing, showing genetic relationship of bacterial isolate TMC-15(MN721337) to other closely related sequences obtained from the NCBI. The 16S rRNA gene sequence of Actinomycetales bacterium was used as an outgrowth. Accession numbers of the sequences are shown in parentheses after the strain name. The numbers at nodes are percentage bootstrap values

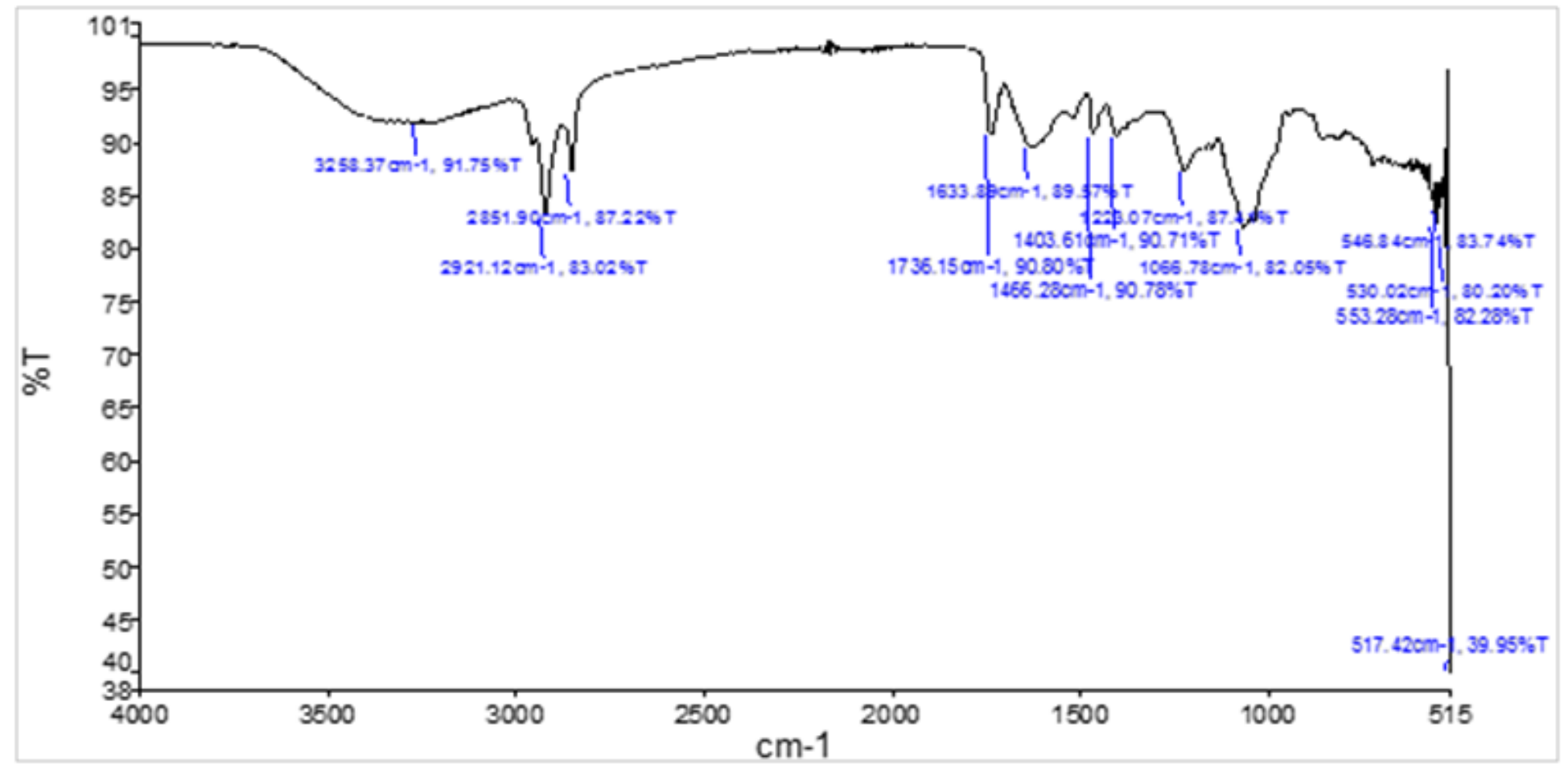

\section{Figure 3}

FTIR Analysis of purified extract isolated from strain TMC-15 


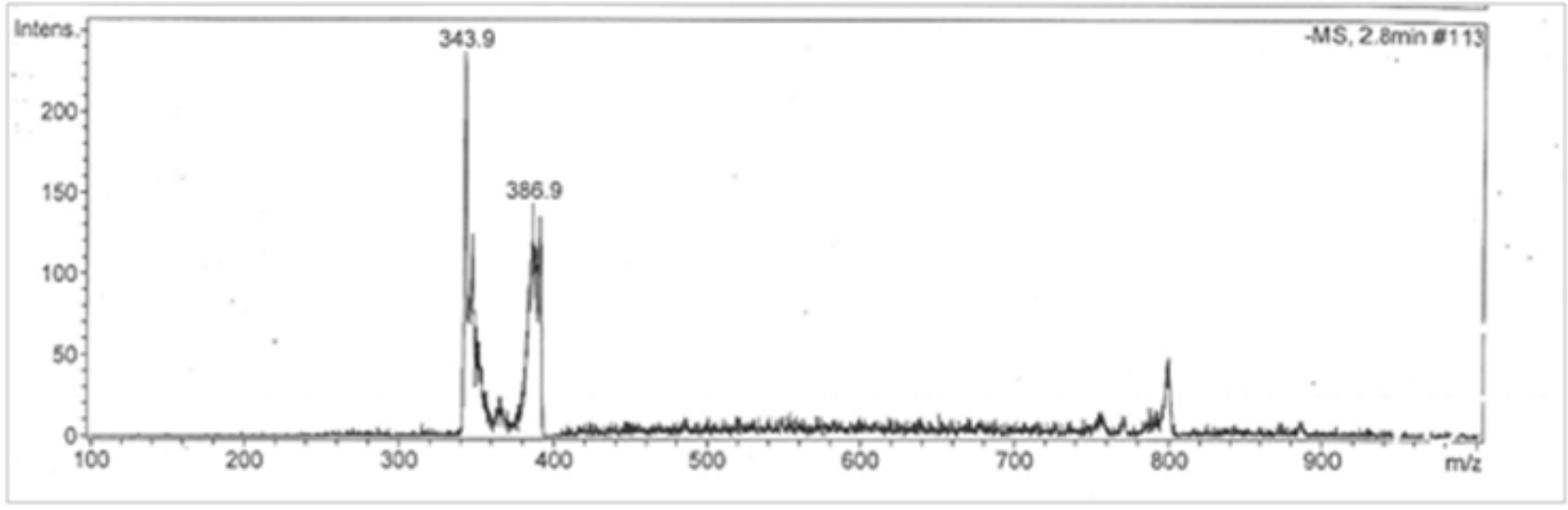

\section{Figure 4}

LC-MS chromatogram/negative MS spectrum of purified the metabolic extract. The compound was identified by signals at $\mathrm{m} / \mathrm{z}$ of 343.9 and $386.9\left[\mathrm{M}+\mathrm{H}^{-}\right.$

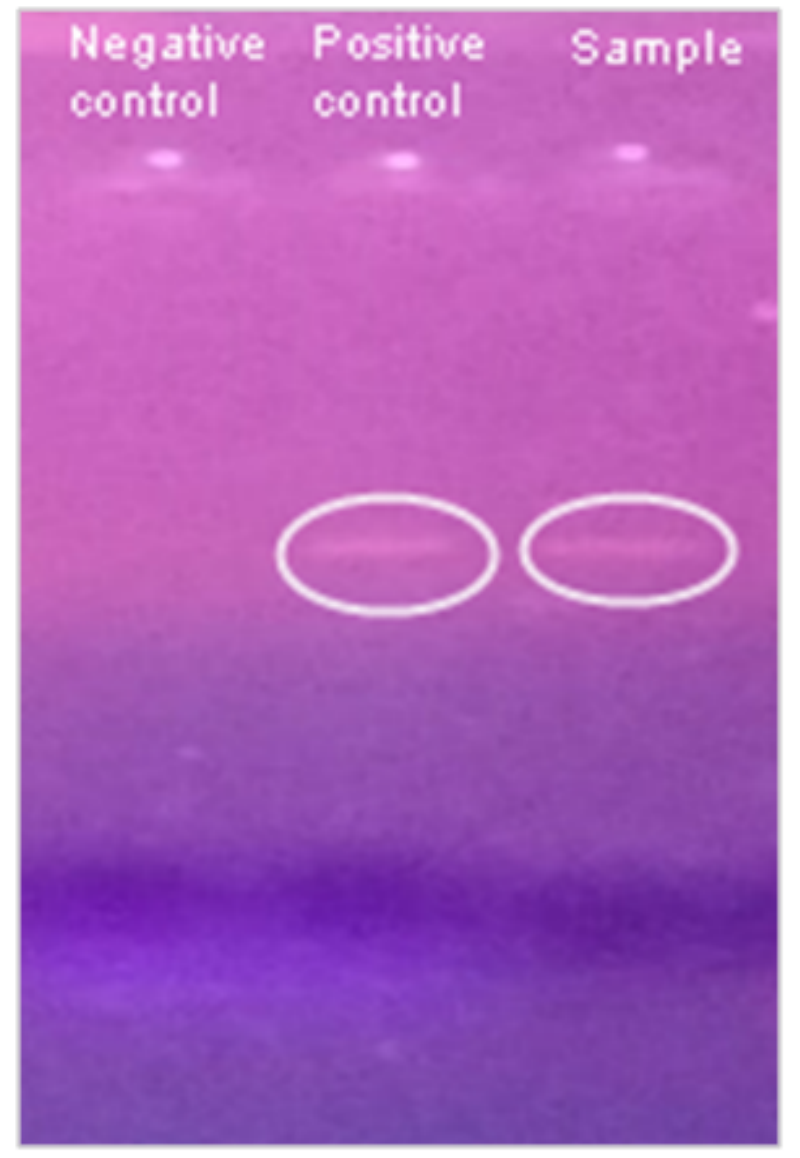

Figure 5

DNA damage prevention assay. Lane PC represents positive control containing pUC18. Lane NC displayed negative control without any antioxidant. Sample lane contains pUC18 treated with intracellular extract from strain TMC-15. The gel photo has no letter codes (PC, NC) 


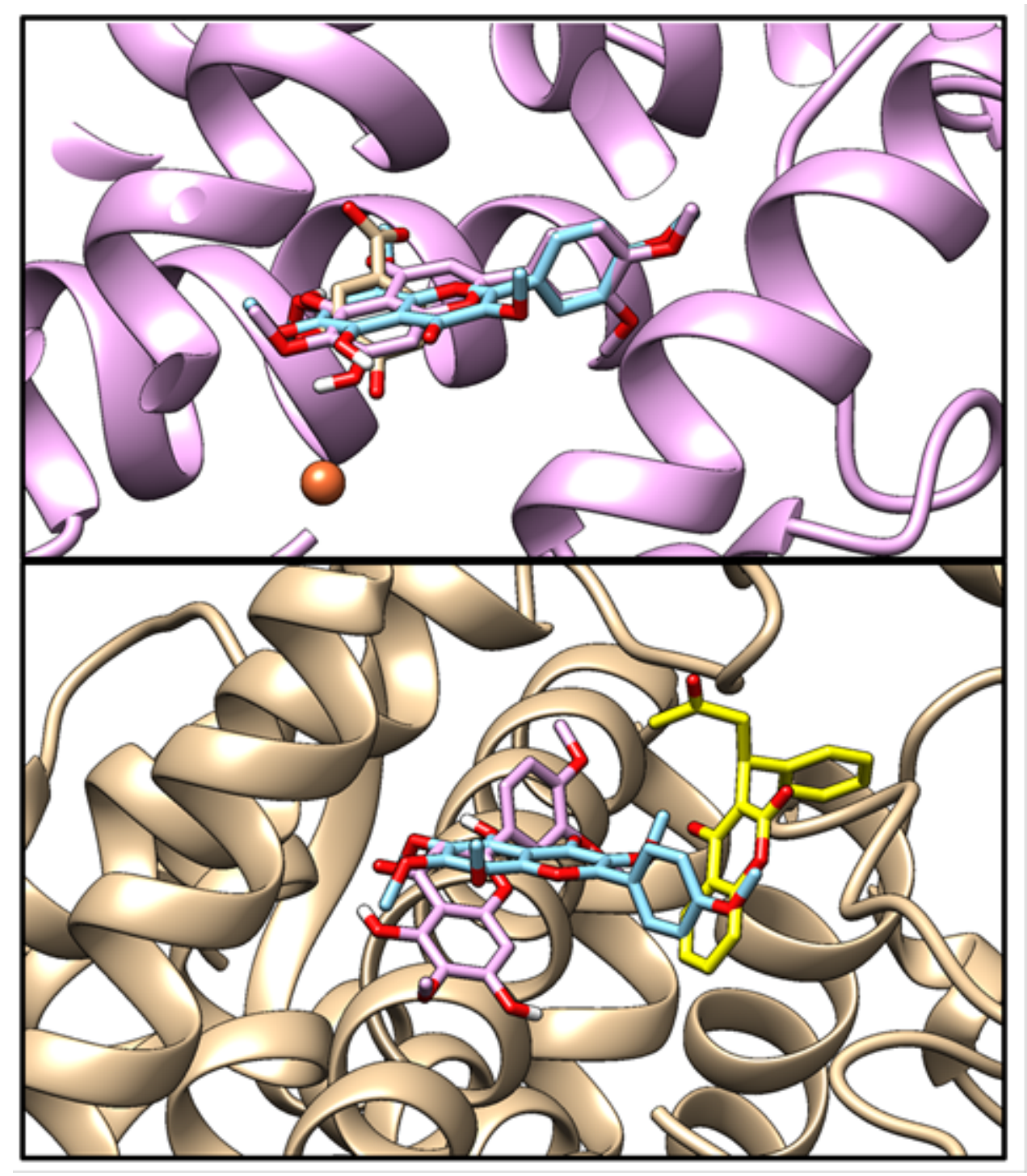

Figure 6

Binding mode of the compounds at docked position of 1N8Q (top) and 10G5 (bottom). The control (protocatecuic acid) in case of IN8Q (colored as plum cartoon) is shown in tan, whereas as yellow (swarfarin) in 10G5 (colored as tan cartoon). Compounds 5-hydroxyauranetin and Eupatilin are presented by sky blue and plum, respectively in both receptors 


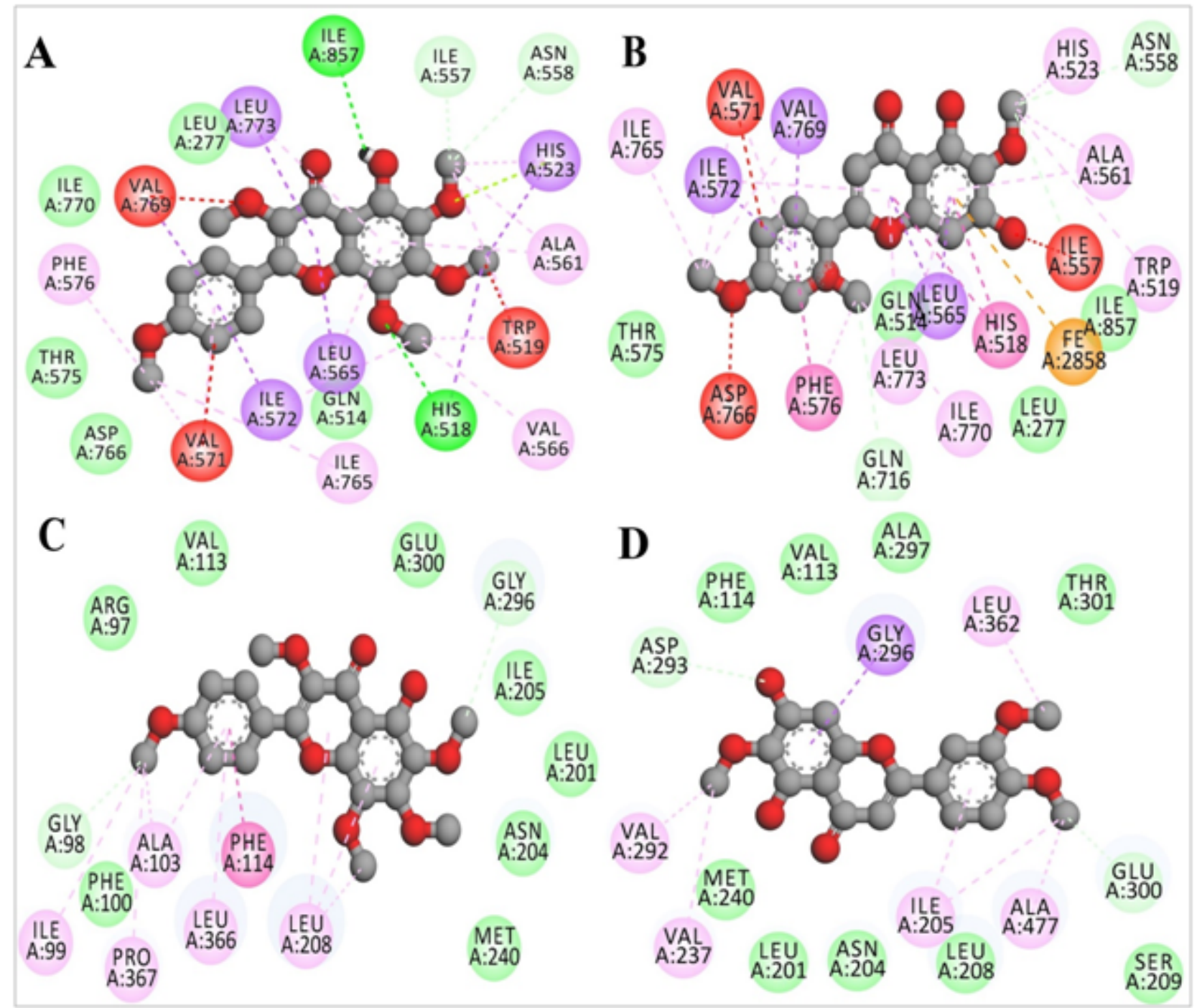

Figure 7

Chemical interactions of the compounds to the proteins at the docked sites. Coloring of the interactions can be interpreted as light green (van der Waals), red (unfavorable bump), dark green (conventional hydrogen bond), aquamarine (carbon hydrogen bond), purple (pi-sigma), pink (alkyl, pi-alkyl), orange (pianion), and fuscia (pi-pi T-shaped) 

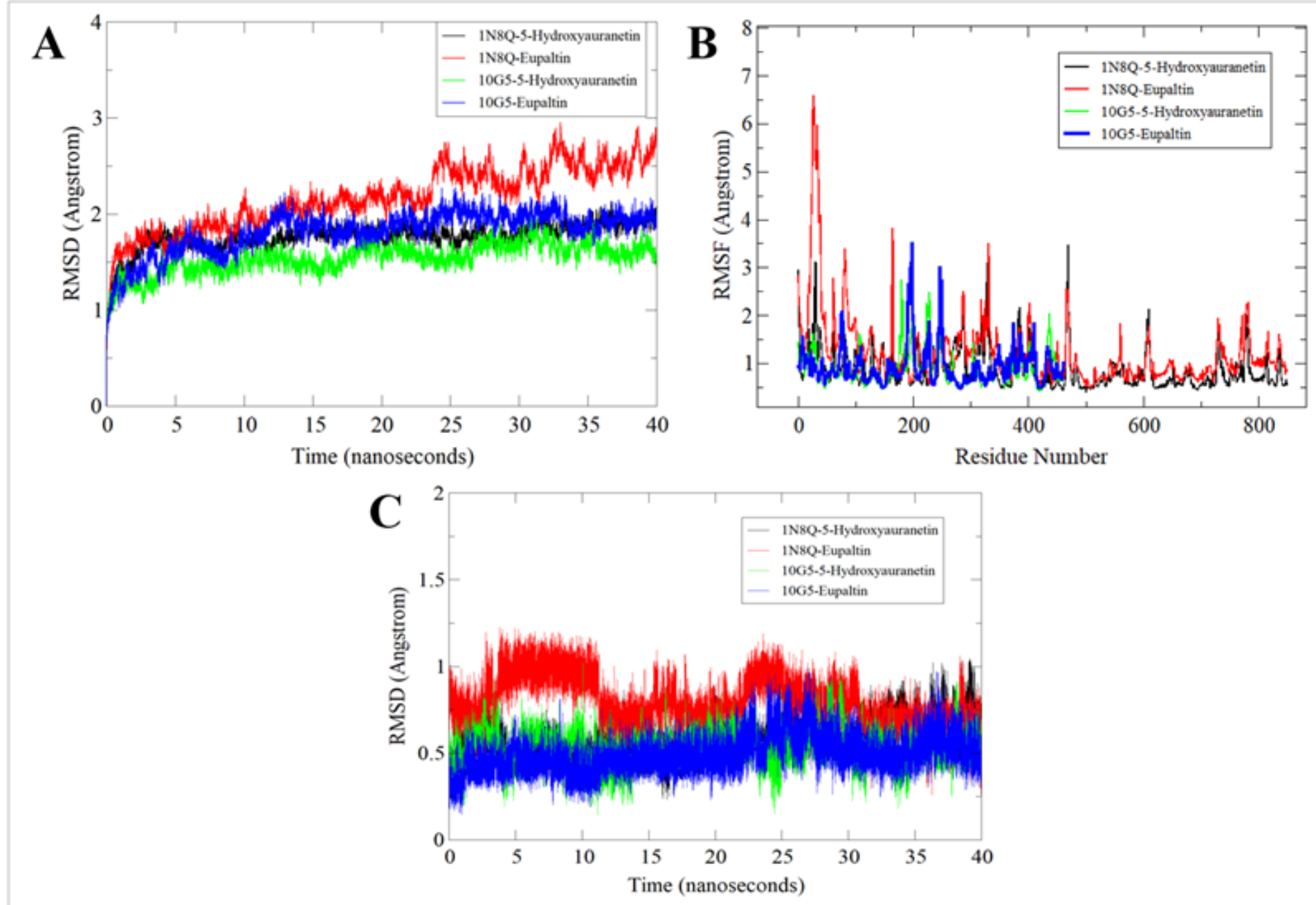

Figure 8

MD simulation analysis. Enzymes RMSD in the presence of compounds (A), Enzymes RMSF in the presence of compounds, and compounds RMSD at the docked site of the enzymes (C)

\section{Supplementary Files}

This is a list of supplementary files associated with this preprint. Click to download.

- Authorchecklist.docx 